\title{
Towards a Strategic Understanding of Global Teams and their HR Implications: A Practitioner's View
}

\author{
Dr. Teck Choon TEO, DBA \\ Associate Professor \\ American University of Phnom Penh, Cambodia \\ Prof. Dr. Kim Cheng Patrick LOW, Ph.D \\ Chartered Marketer/ Certified MBTI Administrator \\ $\&$ Certified Behavioural Consultant \\ Independent Consultant/ Visiting Professor, \\ Strategic Management/ Human Resource Management \\ Graduate School of Business, The University of the South Pacific, Suva, Fiji
}

\begin{abstract}
The age of liberalisation and globalisation along with the artificial intelligence, automation, and other advancements in information technology specifically set the stage for more technological evolution. Robotics are becoming smarter, and even our thermostats and refrigerators can be connected to the internet. The extended use of information systems has a profound impact in the way HRM is currently managed. It boosted a major transformation of human resources $(H R)$ processes and practices within organisations, namely on how they collect, store, use, and share information. This paper focuses on the theoretical framework of international HRM and highlights the trends and challenges of the International and Multi-National Companies.
\end{abstract}

Keywords: Workforce demographics, technology, corporate responsibility, cultural diversity.

\section{Introduction}

International Human Resource Management (IHRM) has long been established as an imperative and integral part in management studies, and one which is key to the success of global organisations. In the globalisation process, business success would depend on how competitive the firms are vis-à-vis to maintain competitiveness; firms must innovate and develop a greater capacity for proactiveness than that of their competitors. As organisations and societies are becoming more diverse, many businesspeople with different cultural backgrounds are expected to collaborate with each other; but they tend to cling to their national interests and priorities which runs counter to globalisation. Resulting in organisations finding desperately new ways of doing business in order to stay ahead of competition. The international business environment has also seen remarkable transformation, namely shifts in the global landscape with the progress of emerging markets and shifts in the ways businesses are done; the rise in strategic business alliances, licensing and contracting, and growth of technology-oriented small and medium sized enterprises (SMEs) and multi-national corporations (MNCs) (Mayerhofer et al, 2004; Sparrow, 2012).

Against this backdrop of an increasing pace of internationalisation and the changing forms of globalisation, varied sources of MNCs growth, lack of certainty on how to internationalise the HRM function and perennial debates on the handling and management of international assignments and the need of new perspectives (Collings et al, 2015; Tung, 2016). In the past, where the United States and Western Europe hold much economic power and stride, but all these have changed, with the heightened economic development of Asian countries. Consequently, transition in intercultural communication competence is required and expected to occur. Presently, with the magnitude of changes in commerce and technology, how do enterprises respond effectively to the change in communication? How will HR function be diminished or strengthened in response to these changes (Collings, Scullion, \& Morley, 2007; Sparrow, 2012).

In exploring the mosaic of the globalisation today, it can be argued that organisations need to develop a more in-depth understanding of international human resource management and its associated activities. In the contemporary landscape of international human resource management (IHRM); strategy, human resource management and organisational performance; international assignments and global careers; knowledge management and human capital development; and multinational corporations; and their impact on human resource management, employment relations and collective bargaining, together seek to explore the origin and scope of the field of IHRM and diverse context in which it is practiced and the emerging debates on performances. 


\subsection{Dominant lines of enquiry}

Morris et al (2009) assert that global firms often struggle to replicate practices among their culturally and geographically dispersed subsidiaries. Part of the reason for this is that certain practices, including human resource management (HRM) practices, are complex and context specific (p. 293). This dominant line of enquiry highlights an important point that is associated to a host of issues surrounding IHRM namely successful replication of IHRM practices across geographically dispersed global countries (Morris et al., 2009), global talent management (Gordon, 2010; Silzer \& Dowell, 2010), and cultural diversity (Scroggins \& Benson, 2010). In addition, other HRM practices affected by business growth strategies include rewards, compensation, and the union (SHRM 2018). Without a doubt that as the economy grows and the job market evolves from an employer to a candidate-driven market, it is indispensable that companies leverage their benefits to recruit and retain top talent.

In a similar vein, organisations increasingly are functioning on a global basis and perspective. Multinational corporations (MNCs) require not only coordination of international strategy, but also the resources vis-à-vis human capital, and organisation to implement it. The concerns of internationalisation both for organisations and their human resource practices gravitate towards developing an understanding of the processes involved and to formulate their own strategic solutions. Invariably, in today's IHRM context, there is an emphasis on companies to engage in corporate sustainability (CS) and corporate social responsibility (CSR) in order to address the current crisis of confidence in business, align activities with the needs and expectations of a broader set of stakeholders, and help tackle the world's ostentatious challenges. Hence, a new understanding of the purpose of IHRM is needed if it is to be effective in both designing and implementing sustainable IHRM systems and contributing to solving today's ostentatious challenges. Dyllick and Muff (2016) developed a business sustainability typology highlighting the necessary shifts required for a paradigm change.

Dyllick and Muff (2016) posited that initiatives put forth by corporations have failed to address the ostentatious challenges of our times. These failures underscore the crucial need for a new common good business and HRM model. Moreover, current developments suggest that millennials are attracted to jobs that serve a purpose (Gong et al, 2018), higher CSR (corporate social responsibility) expectations of customers (Joshi \& Rahman, 2015) and more government and investors' pressure on companies to serve the common good (Crifo, Durand, \& Gond, 2019) are likely to stimulate businesses to adopt such an approach.

\section{Literature Review}

The labour market is characterised by an excess supply of workers, and a deficit of talents and of necessary skills, for more reasons (Yang, 2019; Gershon, 2017; McKinsey, 2012). We have seen in the last 30 years, technology has altered how production and operations are done, replacing mostly low-skill workers. Also, there is a low supply of workers with tertiary education with specific skillset or technical knowledge. Conversely, there is a geographic imbalance between the countries that generate employment, and those that do not, or where the unemployment rates are the highest. In some advanced economies, there are talents that are under-utlised: workers older than 55 years old, who are highly knowledgeable and skilled; educated women that prefer taking care of their children.

In a study of the future of evolution of job, The World Economic Forum (2017) asserted that the total loss of jobs will be of 7.1 million $-66 \%$ being concentrated in routine white collars functions, such as Office and Administrative roles globally. On the other hand, two million jobs, will be created, in Computers, Mathematics, Architecture, and Engineering related fields. Unsurprisingly, highly skilled engineers in industrial internet, skilled technicians and specialists to create and manage advanced and automated production systems, highly skilled sales specialists will be in high demand, including robotics, artificial intelligence. Managerial jobs in financial operations, marketing, supply chain, will have a mainly flat aggregate evolution. However, new jobs will be created, most of them did not exist 10 or 5 years ago, $65 \%$ of children entering primary school today will work, when completing studies, in completely new jobs. In the past decade, the global business has transformed rapidly, and now many companies are compelled in chasing multiple objectives. For that reason, they are redefining success in more sustainable terms of Triple Bottom Line, Quadruple Bottom Line and common good outcomes, not just financial criteria (O'Higgins \&Zsolnai, 2017).

According to Caligiuri and Bonache (2016), IHRM is largely slanted towards human resource management, for example developing the international expertise of a relatively small number of employees through various types of international assignments. It is anticipated that many global organisations are facing HR challenges vis-à-vis moving away from traditional hierarchy-based to more flexible, team-based structures (Schwartz, Bohdal-Spiegelhoff, Gretczko, \& Sloan, 2016; Zander et al., 2015). 
Other writers like Cascio \& Boudreau (2016); Tung (2016) also support the key roles of HR in the global team, and more specifically in the development and maintenance of a coordinated HR system which taps into the potential of global team members including processes for the continuity of core HR practices, such as appropriate recruitment and selection, training, career development, developing global leaders who possess global mindsets, managing international assignments, and global talent management.

The labour force demographics are also changing, for example, more millennials will need to work together with workers from generation $\mathrm{X}$ who will retire much later, increasingly more women, more immigrants will be present in the work environment. Millennials (Gallup 2016, Mirza 2018, Jenkins 2019) are immensely different from the other generations of workers, being raised differently as previous generations. Without a doubt, the common theme across these generational shifts is technology. It is no longer just means for automation, efficiency, and productivity. The evolution of technology has become the biggest influencer of human mindset, preference, and behavior.

With the perpetual shift of organisational environment, the HRM is now in transition (Ehnert, 2014) and a multidimensional sustainable HRM model is evolving that takes into account long-term influences such as climate change, biodiversity, urbanisation, and workforce demographics rather than the traditional bottom-line profit and loss and ROI (return on investment). Moreover, natural resources and social capital are perceived as important as economic capital. Subsequently, these resources need to be sustainable via the development of "people-management practices that take the development of social, environmental and human capital into account" (Guerci \& Carollo, 2016, p. 212).

\subsection{Emerging Trends/Challenges facing HRM/IHRM}

The advent of disruptive management and rapid technological advances necessitate SBUs (Strategic Business Units) within the organisation to provide and support sustainability while addressing the rising customer expectations. It is a compelling challenge for the SBUs to mitigate the issues that are prone to emerge as impediments in the way of seamless operation vis-à-vis key trends and challenges for international HRM (e.g. technology, education, mobility, cultural diversity, CSR, etc.) and how these trends and challenges impact upon and affect the HRM practices for an MNC.

Most of the leading organisations have incorporated the technological advancement in order to cope with the unpredictability of the business environment. The MNCs (Multi-National Corporations) are facing a significant swing in terms of HRM policies due to the advent cross-migratory trading to gain a relative competitive edge.

\section{Methodology}

The study employed qualitative case study design to collect and analyse the data. It involved in-depth interviews to facilitate understanding of IHRM impacting on performance and the emerging themes and contemporary debates in Southeast Asia, in particular Myanmar, Singapore and Cambodia. (Kegler et al 2019). This approach holds promising directions for global organisational survival and performance. Organisations that use benefits as a strategic tool for hiring and retaining talent reported better overall company performance and above-average effectiveness in recruitment and retention compared with organisations that did not (SHRM 2017).

This study was conducted by means of both primary and secondary sources of data. Interviews formed the basis for the primary sources of data. A semi-structured interview guide was designed for the respondents. Out of 320 invitations to participate in the qualitative survey, only 120 (or 37.5\%) respondents accepted the invitation. The 120 respondents were put into groups according to their industry sector. Focus group discussions were then held with the respondents. Respondents' opinions were solicited on the organisation's leadership style and its impact on the performance and survival of the organisation. This allows the researchers control over the questioning approach, while giving the respondents sufficient space to provide historical and detailed information where necessary (Creswell, 2007). Also, in order to fully understand the issues being investigated, the one-on-one interview approach was adopted as it is an effective tool which offers researchers an opportunity to get in-depth information. All the focus group discussions were audio-recorded with the respondents' permission. These audio tapes were transcribed verbatim and added to other field notes and analysed manually using hand coding and highlighter pens to colour important texts. Themes so identified were then categorised into major themes with sub-themes for each of the major themes.

\section{Discussion}

\subsection{Changing nature of regional economic landscape}

At present, the pressures on these markets are becoming increasingly apparent. In advanced economies, demand for high-skill labour is now growing faster than supply, while demand for low-skill labour remains weak. From the indepth interviews and data collected, there is an increasing attention drawn to sustainable HRM systems (Pfeffer 2010), as well as HRM systems that support companies in reaching their corporate sustainability (CS) goals (Ehnert, Harry \& 
Zink 2014; Taylor, Osland \& Egri 2012). This reiterate the use of sustainability both as a "means" to reach CS objectives and as an "end" to design HRM practices and process (Taylor et al., 2012). Invariably these practices have impacted not only employees but also the human, social, and environmental contexts of companies (Renwick, Jabbour, Muller-Camen, Redman \& Wilkinson, 2016; Rothenberg, Hull \& Tang 2017).

From the perspective of advanced economies; they will need to intensify the output of young graduates with jobspecific training and exposure vis-à-vis in science, engineering, and other technical fields. These workers will be in high demand, and their contributions will be critical for meeting the rising productivity imperative. In the rapidly evolving business landscape and given the technological advancement, the world is likely to have too many workers without the skills to land full-time employment. In both developing and advanced economies, HR managers will need to find ways to be inclusive; not only to produce high-skilled workers but also to create employments for those who are not as highly educated.

One trend is clear, businesses operating in this skills-scarce world must know where the talent pools with necessary skillset are. By building strategies, can the businesses have the competitive edge. This will include finding ways to retain more highly skilled women or older workers. Businesses will also need to significantly step up their activities in shaping public education and training systems in order to build pipelines of workers with the right skillset for the 21 stcentury global economy.

\subsection{The HR roles are already evolving}

Technological savvy HR departments are already using analytics to predict and assess everything from employee retention to recruitment strategies to the success of wellness programs. The focus for HR today is to create a powerful employee experience which is similar to customer experience. For example, in the field of IHRM, the combined responsibility for HR and IT functions, which essentially leverage machine learning techniques and sophisticated algorithms to automate work and create a consumer experience for employees. Furthermore, the HR's use of data to proactively retain employees and enhance career mobility with learning opportunities. The data driven initiatives currently are predicting employee retention and signifying which employees in the company are likely deserving of recognition through a merit increase.

\subsection{Identification of key trends and challenges}

It is imperative for any MNCs to acquire the ability of operating globally. Evidently human resource manager of any company needs to ensure sustainable recruitment which is instrumental in ensuring that the company is equally accepted in the global market. As a human resource manager of the company the major challenge is associated with recruitment of the appropriate employees that can ensure organizational success in the global paradigm. The major challenges from the information gathered from the interviews have been identified in the field of HRM trends and practices are:

\begin{tabular}{|l|l|}
\hline HRM & IHRM \\
\hline Workforce Demographics e.g. Millennials & Cultural diversity \\
Technology e.g. Data Analytics, AI, Robotics, & Laws \& Regulations of Host Countries \\
Digital & \\
CSR & \\
\hline
\end{tabular}

\subsection{Specific Impact on HRM}

\subsubsection{Demographics: Job design, motivation (measures/outcomes, rewards/recognition)}

According to Gallup et al (2016) and Hogan (2014) The work force demographics has evolved: more millennials are working together with generation $\mathrm{X}$ workers who are retiring much later, more women, more immigrants are in the work environment. The millennials are differing acutely from the other generations of workers, being brought up differently as previous generations; they grew up with extensive access information due to technology, and are attuned, through social media, to what other people think, or feel in their jobs. As a result, millennials have a unique set of values, needs, and world view vis-a-vis, far less willing to sacrifice their life for work, expecting to be judged on their performance, and to receive frequent feed-back. They are not loyal to their organisations, constantly on a look out for new job opportunities, until they find worthwhile, meaningful ones that they can identify with. For example, strong employer brand, and where their strengths and contribution are valued. Invariably, human resources strategies are challenged by dramatic changes, primarily in areas of jobs and work force. Precisely because of dramatic shift in job expectation; a new set of knowledge, skills, and attitudes are obligatory. Many traditional jobs will be lost, and the society will be divided in low skilled/low paid and highly skilled/highly paid employees. 
As chronic unemployment will rise. It is interesting that entrepreneurship is being encouraged by governments as compensating lever for corporate layoffs. Fostering entrepreneurship, nevertheless, implies new needs and goals, that must be understood and met by leaders, in order to engage employees

4.4.2 Technology: In the digital economy, which has to do with the tech ecosystem and the talent, and digital readiness. There will be new jobs, some traditional jobs will be irrelevant and will be lost, some jobs will be redesigned, which trigger management to implement continuous learning/training, role changes, etc.

There is the impact of technology and it tends to have foreseen and unforeseen consequences (Hall \& Martin, 2005) and is socially embedded resulting in disparities in the take up of technologies both in the divergence and convergence in HRM practices. For example, on the one hand, robotics has the potential to displace workers from even quite highly skilled jobs. On the other hand, economies such as the UK and the US, labour has become so inexpensive as to displace machinery even in areas of technological maturity, e.g. the replacement of automatic car washes by hand ones (Clark \& Colling, 2019). In today's staff-centric work environment vis virtual working are enabling employment to be accessible and facilitate a better work life balances, companies are harnessing the global labour forces (Lipnack \& Stamps, 2008). Conversely, it greatly reduced interpersonal contact, making informal communication and the sharing of ideas, and the building of shared organizational identities, much more difficult; hence making organisations more disjointed. Rapid technological advances in digitization and Big data, analytics have been restructuring the business landscape, boosting performance, and enabling the emergence of new business innovations and new forms of competition. Simultaneously, the technology itself continues to evolve, bringing new waves of advances in robotics, analytics, and artificial intelligence (AI), and especially machine learning. Taken together, it represents a significant transformation in technical capabilities that could have profound implications for business, for the economy, and more broadly, for society (Manyika et al 2017).

4.4.3 CSR: From an internal standpoint, organisational-level sustainability initiatives are really concerned with managing business risk management vis-à-vis abating risks and enhancing shareholder value (Shen and Benson, 2016). But from an external standpoint, the purpose of the organisation is to make "a positive contribution to overcome sustainability issues and [to serve] the common good" (Dyllick and Muff, 2016); and a typical question is "How can business use its resources, competencies, and experiences in such a way as to make them useful for addressing some of the big economic, social or environmental challenges that society is confronted with, e.g., climate, migration, corruption, water, poverty, pandemics, youth unemployment, sovereign debt overload, or financial instability?" (Dyllick and Muff, 2016:165). Businesses are progressively seeing corporate sustainability within their respective portfolio of economic activities (Schaltegger et.al. 2012). Corporate sustainability management is increasingly challenged by fundamentally changing market conditions, particularly in terms of innovation and business-model development (evolution) on the one hand, and socio-cultural contexts, on the other.

4.4.4 Cultural diversity: Today's workplace profile is changing, workers are keen to work for longer, upskilling themselves and contributing their invaluable experience. They work alongside and mentor younger colleagues, who bring different perspectives and skills. Increasingly, we are seeing more multi-generational workplaces. We also need workplaces that provide flexible work arrangements, so that workers can pursue their aspirations at the workplace, while having support to start a family, take care of their parents, or have other pursuits (Samuel and Odor, 2018). This requires employers to have a progressive mindset. Thus, the human capital is central to any organisation since it forms the engine that drives that organisation. As the organisation seeks to achieve its purposes, it requires competent managers to run the other factors of production. More importantly, therefore is to have in place the right persons with the correct professional, academic and social skills for the various functions. In order to achieve this, organisations must be able access wider pool of sources, for example, individuals drawn from different geographical, social cultural and political background and not being constrained by specific group of workers.

Organisations need to focus on diversity and find ways to become totally inclusive organisations because diversity has the potential of yielding greater productivity and competitive advantages. A diverse workforce reflects a changing world and marketplace. Diverse work teams bring tremendous value to organisations. Respecting individual differences will benefit the workplace by creating a competitive edge and increasing work productivity. Diversity management creates a fair and safe environment where everyone has access to opportunities and challenges. Management tools in a diverse workforce should be used to educate everyone about diversity and its issues, including laws and regulations. Most workplaces are made up of diverse cultures, so organizations need to learn how to adapt to be successful (Coleman, 2013). Diversity is an important organisational resource that can help an organisation gain a competitive advantage (Jones and George, 2011). The authors assert that developing and implementing cross-cultural competence is an appropriate strategy in human capital that supports business endeavours (Silzer \& Dowell, 2010). Nevertheless, cross-cultural competence includes more than hiring diverse leadership, language training, or diversity training. 
It critically encompasses the creation of an atmosphere of inclusiveness that distinguishes organisations that have reached the level of cross-cultural competency. Moreover, the authors believe that MNCs could more precisely classify global training needs by conducting assessments of cultural competency within and between their organisations (Barrera, 2010).

\subsubsection{Laws \& Regulations of Host Countries:}

Given the dynamics employment and globalisations, it resulted in calls for more sustainable management, procedural control, institutional governance, and political accountability (Rodriguez, Johnstone and Procter 2017). For this reason, there is acute attention to regulation, its terms, nature and quality, and its role to shape the employment relationship.

An important concern for international and comparative human resource management (I/CHRM) is understanding the role of regulation in interacting with these changes and how this varies across within and between countries. Regulation is at the centre of competing economic and social demands, which are perceived as both complementary and at the same time conflicting. It suggests that engaging with the paradoxes and ambiguities of different competing agendas of regulation of work, employment and exploring these in relation to different social actors within and across geographies is a significant step in advancing research in this area.

\section{Avenues for future research}

The business environment has changed tremendously i.e. global, complex, dynamic, highly competitive, and extremely volatile. This is likely to persist for many years to come, with many businesses facing talent diaspora; dealing with two generations of workers, vis-à-vis mature or experienced workers and inexperienced young workers; and a shortage of desirable competencies. One major outcome of these challenges for organisations is that they have to be global and that they have to be systematic in managing their human capital if they wish to have any hope of gaining and sustaining a competitive advantage in the years ahead. It also highlights the potential role of IHRM activities in addressing those identified challenges. Hopefully this integrative outline may guide further academic research on global talent management and might also inform the work of HR professionals.

\section{Conclusion}

In summary, the authors reiterate that it is imperative and necessitate HR practitioners to engage HR into forefront of business processes. Consequently, re-shape the HR architecture around the local host country practices and laws, underpinning the values held by that host country's potential workforces and stakeholders. As stated before, the key to launch the transformation process is sensitivity to diverse cultural differences, as well as flexible global HR practices that add value to organisational goals. With the advancement of IHRM, further studies and research are warranted to bridge the gap between theory and practice. Furthermore, increased efforts are obligatory if global HRM is to include global management.

\section{References}

Barrera, J. C. (2010). An examination of cross-cultural competence in international business: The case of the subsidiaries. International Business \& Economics Research Journal, 9(1), 41-54.

Caligiuri, P., \&Bonache, J. (2016). Evolving and enduring challenges in global mobility. Journal of World Business, $51,127-141$.

Clark, I. and Colling, T. (2019). New Insights into Informal Migrant Employment: Hand Car Washes in a Mid-Sized English City. Economic and Industrial Democracy. 40(3). 755-775.

Collings, D. G., Scullion, H., \& Morley, M. J. (2007). Changing patterns of global staffing in the multinational enterprise: Challenges to the conventional expatriate assignment and emerging alternatives. Journal of World Business, 42, 198-213.

Collings, D. G., Wood, G. T., \& Caligiuri, P. M. (Eds.). (2015). The Routledge companion to international human resource management. New York, NY: Routledge.

Coleman, J. (2013). Six components of a great corporate culture. https://hbr.org/2013/05/six-components-of-culture/ accessed on 6 January 2020.

Creswell, J.W. (2007). Qualitative Inquiry and Research Design: Choosing among Five Approaches. Thousand Oaks, California: Sage Publications Inc.

Dyllick, T., Muff, K. (2016). Clarifying the meaning of sustainable business: Introducing a typology from business-asusual to true business sustainability, Organization \& Environment, 29 (2) pp. 156-174. 
Ehnert, I., Parsa, S., Roper, I., Wagner, M., Muller-Camen M. (2016). Reporting on sustainability and HRM: A comparative study of sustainability reporting practices by the world's largest companies, International Journal of Human Resource Management, 27 (1), 88-108.

Friedman, B. A. (2007). Globalization implications for human resource management roles. Employee Responsibilities and Rights Journal,19(3), 157-157. doi:10.1007/s10672-007-9043-1.

Gallup report, (2016), How Millennials Want to Work and Live, www.gallup.com/reports/189830/millennials-worklive.aspx, accessed on 13 September 2019.

Gershon, I. (2017). Down and Out in the New Economy: How People Find (or Don't Find) Work Today. University of Chicago Press.

Gong, B., Greenwood, R.A., Hoyte, D., Ramkissoon, A., He, X., (2018). Millennials and organizational citizenship behavior: The role of job crafting and career anchor on service, Management Research Review, 41 (7) (2018), pp. 774-788.

Gordon, E. E. (2010). Talent challenge: Renewing the vision. T+D, 64(6), 42-47.

Guerci, M., Carollo, L. (2016). A paradox view on green human resource management: Insights from the Italian context, The International Journal of Human Resource Management, 27 (2) (2016), 212-238.

Hall, J.K. \& Martin, Michael J. C. (2005). Disruptive technologies, stakeholders and the innovation value-added chain: a framework for evaluating radical technology development. R\&D Management, 35(3), 273-284.

Hogan M. (2014). Employee Engagement Doesn't Equal Employee Happiness, Forbes, https://www.forbes.com/sites/yec/2014/05/20/employee-engagement-doesntequal-employeehappiness/\#6252102c2413.

Jenkins, J. (2019). Leading the Four Generations at Work, AMA articles, https://www.amanet.org/articles/leading-thefour-generations-at-work/ accessed on 13 September 2019.

Jones, GR; George, JM. (2011). Essentials of contemporary management. Boston : McGraw-Hill/Irwin, 4th edition.

Kegler, Michelle C., Raskind, Ilana G., Comeau, Dawn L., Griffith, Derek M., Cooper, Hannah L. F., Shelton, Rachel C. (2019). Study Design and Use of Inquiry Frameworks in Qualitative Research, Health Education \& Behavior, 46(1), pp. 24-31.

Lipnack, J. \& Stamps, J. (2008). Virtual Teams: People Working Across Boundaries with Technology. John Wiley \& Sons. ISBN $0470438959,9780470438954$.

Manyika, J.,Chui, M., Madgavkar, A., and Lund, S. (2017). What's now and next in analytics, AI, and automation Executive briefing. McKinsey Global Institute. Available at https://www.mckinsey.com/featuredinsights/digital-disruption/whats-now-and-next-in-analytics-ai-and-automation accessed on 3 Jan 2020.

Mayerhofer, H., Hartmann, L. C., Michelitsch-Riedl, G., \&Kollinger, I. (2004). Flexpatriate assignments: A neglected issue in global staffing. The International Journal of Human Resource Management, 15, 1371-1389.

McKinsey Global Institute. (2012). The world at work: Jobs, pay, and skills for 3.5 billion people, available at www.mckinsey.com/global-themes/employment-and-growth/the-world-at-work. accessed on 13 September 2019

Mirza, A. (2018). Employers: Getting Gen-X \& Millennials to Work Together, Hongkiat, https://www.hongkiat.com/blog/making-gen-X-millennials-work-together/ accessed on 13 September 2019.

Morris, S. S., Wright, P. M., Trevor, J., Stiles, P., Stahl, G. K., Snell, S., \&Farndale, E. (2009). Global challenges to replicating HR: The role of people, processes, and systems. Human Resource Management,48(6),973-995.

O’Higgins, E., Zsolnai, L. (2017), (Eds.), Progressive business models: Creating sustainable and pro-social enterprise, Springer, Cham.

Pfeffer, J. (2010). Building sustainable organizations: The human factor, Academy of Management Perspectives, 24 (1) (2010), 34-45.

Renwick, D.W., Jabbour, C.J., Muller-Camen, M., Redman, T., Wilkinson, A. (2016). Contemporary developments in Green (environmental) HRM scholarship. International Journal of Human Resource Management, 27 (2) (2016), pp. 114-128.

Rodriguez, J.K., Johnstone, S., and Procter, S. (2017). Regulation of work and employment: advances, tensions and future directions in research in international and comparative HRM. The International Journal of Human Resource Management, 28(21), 2957-2982.

Samuel, Ajiri\& Odor, Hillary. (2018). Managing Diversity at Work: Key to Organisational Survival. European Journal of International Management. 10(16).

Schaltegger, S., Hörisch, J., Windolph, S. E., \& Harms, D. (2012). Corporate Sustainability Barometer 2012: Praxisstand und Fortschritt des Nachhaltigkeitsmanagements in den größtenUnternehmenDeutschlands. Lüneburg: Centre for Sustainability Management. 
Schwartz, J., Bohdal-Spiegelhoff, U., Gretczko, M., \& Sloan, N. (2016). The new organization: Different by design. Global human capital trends 2016. Deloitte University Press, 124 p.

Scroggins, W. A. \& Benson, P. G. (2010). International human resource management: Diversity, issues and challenges. Personnel Review, 39(4), 409-413. doi: 10.1108/00483481011045380

Shen, J. and Benson, J. (2016). When CSR is a social norm: How socially responsible human resource management affects employee work behavior. Journal of Management, 42 (6) (2016), 1723-1746.

SHRM (2017) - Society for Human Resource Management. 2017 Strategic Benefits Survey—Strategize with Benefits. Retrieved from www.shrm.org.

SHRM (2018) - Society for Human Resource Management. 2018 Employee benefit survey https://www.shrm.org/hr-today/trends-and-forecasting/research-andsurveys/Documents/2018\%20Employee\%20Benefits\%20Report.pdf accessed on 16 September 2019.

Silzer, R., \& Dowell, B.E. (Eds.). (2010). Strategy-driven talent management: A leadership imperative. San Francisco, CA: Jossey-Bass.

Sparrow, P. (2012). Globalising the international mobility function: The role of emerging markets, flexibility and strategic delivery models. The International Journal of Human Resource Management, 23(12), 2404-2427.

Taylor, S., Osland, J., Egri, C.P. (2012). Introduction to HRM's role in sustainability: Systems, strategies, and practices. Human Resource Management, 51 (6) (2012), pp. 789-798.

The world Economic Forum report. (2017). Preparing for Fourth Industrial Revolution Requires Deeper Commitments to Education, www.weforum.org/press/2017/01/ preparing-for-fourth-industrial-revolution-requires-deeper-commitments-to-education/.

Tung, R. L. (2016). New perspectives on human resource management in a global context. Journal of World Business, $51,142-152$.

Yang, A. (2019). The War on Normal People: The Truth About America's Disappearing Jobs and Why Universal Basic Income Is Our Future, Hachette Books. New York.

Zander, L., Butler, C. L., Mockaitis, A. I., Herbert, K., Lauring, J., Mäkelä, K., Zettinig, P. (2015). Team-based global organizations: The future of global organizing. Progress in International Business Research, 10, 227-243. 